\title{
O INTRAEMPREENDEDORISMO NAS SOCIEDADES COOPERATIVAS: O CASO DE UMA COOPERATIVA DO SETOR DE SERVIÇOS NO ESTADO DO RIO GRANDE DO SUL
}

\author{
Gustavo Fontinelli Rossés* \\ Carla Rosane da Costa Sccott** \\ Leoni Pentiado Godoy ${ }^{* * *}$ \\ João Hélvio Righi de Oliveira**** \\ Claudinei Viero*****
}

\begin{abstract}
RESUMO: As últimas décadas constituíram um período de modificações no que se refere aos estudos das cooperativas. Inúmeras discussões emergiram no sentido de dar maior compreensão para temática tão vasta que norteiam o empreendedor e o intraempreendedor. Tal situação requer iniciativas que proporcionem um ambiente seguro e desafiador para a propagação de ideias, evidenciando a ação intraempreendedora. Diante disso, esse estudo tem como objetivo "avaliar o perfil do presidente de uma cooperativa de serviços localizada no RS, sob as perspectivas das dimensões intraempreendedoras". Para tanto, foram aderidas contribuições teóricas de distintos autores que permitissem delinear características para avaliar o perfil intraempreendedor. Dessa forma, lançou-se mão de estudo do tipo qualitativo, com característica descritiva, sob a ótica de um estudo de caso. Tomou-se como base uma cooperativa do setor de serviços no RS, onde foram entrevistados o presidente e mais três pessoas ligadas diretamente ao mesmo, para que se pudesse confrontar as respostas. Como resultados, foi possível observar que o presidente atende a maior parte dos requisitos do modelo, porém, foi constatada uma limitação no que tange à dimensão do monitoramento, no qual foi possível propor um modelo adequado a essa necessidade, como contribuição maior.
\end{abstract}

PALAVRAS-CHAVE: Cooperativa; Intraempreendedorismo; Setor de serviços.

\footnotetext{
${ }^{*}$ Doutor em Extensão Rural pela UFSM; Docente no Colégio Politécnico da Universidade Federal de Santa Maria (UFSM), Santa Maria (RS), Brasil; E-mail: gustavo@politecnico.ufsm.br

${ }^{* *}$ Mestre em Engenharia de Produção pela UFSM; Docente no Instituto Federal Farroupilha (IF-Farroupilha), Brasil.

${ }^{* * *}$ Doutora em Engenharia de Produção pela UFSM; Docente na Universidade Federal de Santa Maria (UFSM), Santa Maria (RS), Brasil.

${ }^{* * * *}$ Doutor em Engenharia de Produção pela UFSC; Docente titular na Universidade Federal de Santa Maria (UFSM), Santa Maria (RS), Brasil.

${ }^{* * * * *}$ Graduado em Ciências Contábeis pela UFSM; Docente do Centro Universitário Franciscano (UNIFRA), Santa Maria (RS), Brasil
} 


\section{ENTREPRENEURSHIP OF COOPERATIVES: THE CASE OF A SERVICE COOPERATIVE IN THE STATE OF RIO GRANDE DO SUL, BRAZIL}

ABSTRACT: Recently significant changes have occurred in the analysis of cooperatives and numberless discussions have emerged study the theme that directs enterprisers and entrepreneurship. The initiative should provide a safe and challenging haven for the propagation of ideas and the entrepreneurship activity. Current analysis "assesses the profile of a service cooperative's president in the state of Rio Grande do Sul, Brazil, under the point of view of entrepreneurship". Several theoretical opinions have been analyzed to foreground the characteristics of the entrepreneurship profile. Current qualitative and descriptive study is a case study based on a service cooperative in the state of Rio Gande do Sul. The president and three other persons directly linked to the former were interviewed so that the answers could be compared and contrasted. Results show that the president attends to most requirements of the model, with limitations in monitoring. A model was proposed which was adequate to such needs.

KEY WORDS: Cooperative; Entrepreneurship; Service segment.

\section{INTRODUÇÃO}

As últimas décadas constituíram um período de intensas modificações; no que se refere aos estudos das organizações quanto à sua prática efetiva. Inúmeras discussões, complementações, questionamentos e postulações emergiram no sentido de dar maior significado e compreensão para a temática tão vasta e nebulosa que vem à tona, como é o caso do empreendedor e do intraempreendedor.

Fica claro que essas mudanças produziram novos conceitos e abordagens, emergindo um caráter sistêmico e funcionalista, promovendo acumulação consistente e a construção de conhecimentos empíricos, com derivações de suposições teóricas relativamente limitadas (CLEGG; HARDY; NORD, 1999).

As novas formas organizacionais vêm sendo visualizadas basicamente de duas maneiras: a) como representação de uma lógica de ação diferente da instrumental que é típica do modelo modernista de organização (COOPER; BURRELL, 1988; CLEGG, 1990; PARKER, 1992); e b) como simples aperfeiçoamento da abordagem 
contingencial da administração (TSOUKAS, 1992; THOMPSON, 1993; DELLAGNELO; SILVA, 2000, p. 20).

Imersos nessa lógica, advoga-se que as cooperativas têm grandes desafios nessa temática, pois dependem que seus gestores tenham alta capacidade empreendedora de modo a fomentar a congruência de esforços do grupo, bem como proporcionar ganhos de competitividade para as organizações que compõem. Esse conceito ajuda a entender que há dentro de uma economia global capitalista outras formas de produção, como é o caso das associações cooperativas, baseadas nas relações de cooperação, trabalho associado e autogestão, tendo como valor central a ação colaborativa, especialmente aquelas ligadas aos produtores de menor escala.

Sendo assim, para que tal situação seja colocada em prática, se faz necessária a ação iniciativa de uma pessoa ou de um grupo de pessoas que proporcionem um ambiente atrativo, seguro e desafiador para a propagação e a efetivação de ideias. Baron e Shane (2010) evidenciam que essa atitude implica na ação empreendedora, onde esse empreendedor é aquele que faz as coisas acontecerem, se antecipa aos fatos e tem uma visão futura da organização. Já o intraeemprendedor pode ser denominado como uma pessoa que faz parte de uma organização e que está sempre atenta a novas oportunidades, valendo-se dos recursos disponíveis para enfrentar novos desafios.

Para Nassif, Andreassi e Simões (2011, p. 2), "discussões que abordam o empreendedor e o intraempreendedor têm chamado atenção de pesquisadores, acadêmicos e também de empresários", de modo que estudos desta natureza se justificam, uma vez que são poucas as pesquisas que diferenciam o empreendedor do intraempreendedor. Justifica-se, também, devido ao fato que esses atores sociais têm demonstrado valor significativo na economia e, por consequência no mercado, pois estudos como este são diferenciados e necessitam de aprofundamento e melhor compreensão nessas duas dimensões de empreender.

Dornelas (2012) assinala que os últimos 20 anos foram repletos de iniciativas que envolvem os estudos em organizações, sendo que não se pode deixar de lado as análises acerca do empreendedorismo. Isso porque a última década destacou-se por criar as bases para a nova fase do empreendedorismo no país. Esse novo momento começou a ser moldado a partir da constatação da importância do país na visão de 
alguns autores envolvidos com o movimento do empreendedorismo no mundo e, principalmente no Brasil, após a leitura do resultado do primeiro relatório executivo do Global Entrepreunership Monitor (GEM, 2000). Esse estudo tem sido realizado anualmente, destacando a posição brasileira como a décima em termos de criação de novos empreendimentos, cujo índice destaca que de cada 100 pessoas 18 delas desenvolviam algum tipo de atividade empreendedora, correspondendo a mais de 21,1 milhões de pessoas envolvidas em novos negócios.

A ideia que norteia esse trabalho é analisar o perfil intraempreendedor sob a ótica do empreendedorismo em uma cooperativa do setor de serviços, aqui denominada Cooperativa Beta, de modo a identificar as características e atitudes presentes no seu modelo de gestão. Como finalidade tem-se como norte verificar a existência de lacunas na condição empreendedora e, sempre que possível, contribuir para melhoria na gestão cooperativa, bem como qualificar as discussões nesse campo da ciência.

Por oportuno o objetivo geral desse trabalho é: "avaliar o perfil do presidente de uma grande cooperativa do setor de serviços localizada no Rio Grande do Sul, sob as perspectivas das dimensões intraempreendedoras". Para tanto, foram aderidas contribuições de Man e Lau (2000), onde foi possível extrair do modelo do McClelland (1972) características para avaliar o perfil intraempreendedor, foco dessa pesquisa.

A fim de dar melhor entendimento para esse estudo, a seção 2 fundamenta os elementos teóricos intervenientes do empreendedorismo e intraempreendedorismo. Nas seções 3 e 4 são apresentados os requisitos metodológicos, bem como o diagnóstico intraempreendedor. Finalmente, a seção 5 relata as considerações gerais do estudo.

\section{EMPREENDEDORISMO E INTRAEMPREENDEDORISMO}

A literatura tem abordado diferenças entre empreendedores e intraempreendedores, porém, o que se sabe é que todo e qualquer empreendimento necessita de uma gestão eficiente para alcançar o sucesso no mercado, o que denota que constantes buscas de oportunidades, mesmo em período de crise, são 
extremamente necessárias para qualquer segmento empresarial.

Um empreendedor pode ser denominado como aquela pessoa orientada por ações, que realmente faz as coisas acontecerem, estando sempre motivado a assumir riscos calculados, com o intuito de alcançar seus objetivos (McCLELLAND, 1972; NASSIF; GHOBRIL; SILVA, 2010).

Maximiano (2006) reforça, discorrendo que um empreendedor possui algumas características na sua personalidade, tais como: independência e autoconfiança; busca de oportunidades e iniciativa; liderança e persistência. Para o autor, essas características são fundamentais para se iniciar um empreendimento, pois o mercado exige um preparo pró-ativo norteado de ações eficazes. Schumpeter (1985) corrobora quando diz que a essência do empreendedorismo é a inovação que implica a percepção e exploração de novas oportunidades frente a novos negócios.

Para Baron e Shane (2010), o empreendedorismo é o estudo voltado para o desenvolvimento de competências e habilidades relacionadas ao desenvolvimento e execução de algum projeto, que abrange diversos segmentos de negócio, desde um empreendimento no ramo dos serviços como também a venda de produtos. Fleury e Fleury (2000) destacam a importância do empreendedorismo para a geração de riqueza dentro de um país. Para os autores, o ato de empreender promove crescimento econômico e geração de trabalho e renda, oportunizando qualidade de vida para a população.

Imersos nesses conceitos, surgem alguns questionamentos quanto ao que a literatura vem abordando acerca de fundamentações sobre o ato de empreender. Quem é mais empreendedor: aquele que abre seu próprio negócio ou aquele que gerencia uma organização já existente? Onde está o maior desafio, empreender com o desenvolvimento de um novo negócio ou empreender em um negócio já existente? $\mathrm{E}$, por fim, qual a diferença de um empreendedor e um intraempreendedor?

Dentro dessa perspectiva, Hashimoto (2009) advoga que o intraempreendedor é aquela pessoa que está inserida dentro da organização, na figura de colaborador estando sempre atento a novas oportunidades, independente dos recursos que dispõe. Já o empreendedor é aquele indivíduo que abre e gerencia seu próprio negócio, possuindo características inovadoras, estando sempre motivado para enfrentar novos desafios (SCHUMPETER, 1985). 
Pinchot (1985) salienta que o ato de empreender é amplo, e não se limita apenas à criação de uma determinada empresa. Para o autor, conforme a empresa vai evoluindo, o indivíduo pode vir a desenvolver capacidades de um empreendedor corporativo, buscando inovações para organizações já existentes. Para isso, se faz necessário que as organizações aceitem o mundo moderno, com inovações rápidas e comecem a desenvolver projetos para a implantação do empreendedorismo corporativo ou intraempreendedorismo, o qual tem proporcionado benefícios para as empresas em termos de vantagens competitivas, através de novas ideias (DORNELAS, 2012).

Desse modo, utilizou-se como base para avaliar o perfil intraempreendedor do presidente da Cooperativa Beta o modelo proposto por McClelland (1972), cujas carcaterísticas empreendedoras envolvem: conjunto de realizações (busca de oportunidades; persistências; riscos calculados; qualidade e eficiência; e comprometimento), conjunto de planejamento (informações; metas; e planejamento e monitoramento), conjunto de poder (independência e autoconfiaça; persuasão e rede de contatos).

Essa contribuição teórica está fundamentada no comportamento motivacional de um empreendedor, no qual o autor desenvolveu uma metodologia de análise específica, que nesse estudo serviu de referência para permitir extrair um conjunto direcionado a avaliar as características do intraempreendedor. Essas características são emanadas aqui pelas contribuições de Man e Lau (2000), cujas inferências remetem ao objetivo dessa pesquisa, e que contemplam: busca de oportunidades; riscos calculados; comprometimento; informações; metas; planejamento e monitoramento; e persuasão e rede de contatos.

$\mathrm{Na}$ ótica de McClelland (1972), o conjunto de realizações engloba a busca de oportunidades, persistência, riscos calculados, qualidade/eficiência e comprometimento. Para analisar esse conjunto de realizações Man e Lau (2000) contextualizam as seguintes características intraempreendedoras: a busca de oportunidades, riscos calculados e comprometimento. A busca de oportunidades se dá quando o intraempreendedor aproveita as oportunidades para iniciar um negócio, tendo atitudes pró-ativas, ou seja, percebendo o momento de agir. Correr riscos calculados é uma prerrogativa do empreendedor, pois o ato de empreender 
é desafiador e exige maneiras estratégicas para analisar as oportunidades e ameaças existentes no mercado. Por sua vez, o comprometimento é essencial para obter sucesso em qualquer empreendimento, pois é através deste que gera a motivação para sustentar a demanda de um mercado extremamente competitivo (MAN; LAU, 2000).

Para McClelland (1972), o próximo aspecto do perfil empreendedor é o conjunto de planejamento que contempla a busca por informações, metas e planejamento e monitoramento. Man e Lau (2000) discorrem que a busca constante por informações é essencial na construção de estratégias que são delineadas através de análises macro e micro ambientais, bem como são necessárias ao processo de tomada de decisões. O próximo passo é o estabelecimento de metas, que são os objetivos fixados pelo intraempreendedor centrado no alcance dos resultados. Entende-se que essas metas contribuem especialmente para a construção dos demais processos organizacionais. $\mathrm{E}$, por fim, o planejamento e monitoramento compreendem etapas fundamentais no qual o intraempreendedor estabelece uma arquitetura completa dos mais diferentes componentes organizacionais, bem como oferecem aporte necessário para o acompanhamento apropriado dos indicadores de desempenho (MAN; LAU, 2000).

O último aspecto imanado por McClelland (1972) trata do conjunto de poder do empreendedor, onde o autor contempla a independência e autoconfiança e persuasão e rede de contatos. Man e Lau (2000) elucidam que persuasão e rede de contatos são extremamente relevantes no desenvolvimento de relações comerciais, propiciando a credibilidade no produto ou serviço que estão sendo oferecidos, bem como a ampliação de novas ideias e a conquista de novos mercados.

Para McClelland (1972), Man e Lau (2000), Maximiano (2006) e Nassif, Ghobril e Silva (2010), são altas as taxas de abertura de micro e pequenas empresas no mundo inteiro que são encarregadas por uma parcela bastante significativa de geração de empregos.

No entanto, grandes números dessas empresas não alcançam o sucesso e uma das principais causas é a falta de capacidade dos empreendedores em gerenciar suas empresas. Nesse contexto, é validada a eficácia do modelo de Man e Lau (2000) para a realização da análise do perfil intraempreendedor adotado pelo presidente da Cooperativa em questão. 


\section{ASPECTOS METODOLÓGICOS}

De modo inicial, a dimensão de pesquisa no campo científico está enquadrada dentro de alguns instrumentos teóricos. Embora o interesse pelas metodologias qualitativas de pesquisa tenha crescido nos últimos anos, é possível explicitar que se percebe certo grau de desconhecimento em se tratando de suas características, possibilidades e limitações (CASSELL; SYMON, 1994).

Dentre as metodologias menos compreendidas encontra-se, sem dúvida, o método fenomenológico que, nesse estudo, abarca o centro das discussões que se pretende analisar. Uma das dificuldades é o fato da expressão fenomenológica ser utilizada em diversas formas na pesquisa, muitas das quais sem referência de método.

Isso se justifica, pois na visão de Aranha e Martins (2001), as principais dificuldades enfrentadas na questão do método fenomenológico referem-se à complexidade inerente a esses fenômenos, à dificuldade de análise, à questão da experimentação, ao problema da subjetividade e do determinismo, bem como à relação entre o sujeito e o objeto.

O que aparece na consciência é o fenômeno. Fenômeno significa trazer à luz, colocar sob iluminação, mostrar-se a si mesmo em si mesmo, a totalidade do que se mostra diante de nós. Assim, a máxima da fenomenologia: a volta às próprias coisas (MOUSTAKAS, 1994, p. 26).

Sendo assim, essa proposta de estudo caracteriza-se como sendo do tipo qualitativo, fato este comprovado por buscar a identificação das características que envolvem a racionalidade intraempreendedora e suas influências no processo de gestão das organizações, sem deixar de considerar suas implicações dentro da organização em foco. Salienta Triviños (1987, p. 120) que "a pesquisa qualitativa pode ser entendida como uma expressão genérica, pois compreende atividades de investigação que podem ser denominadas específicas, onde todas podem ser caracterizadas por traços comuns". Conforme evidencia Flick (2009, p. 25), "de modo diferente da pesquisa quantitativa, os métodos qualitativos consideram a comunicação do pesquisador em campo como parte explícita da produção de conhecimento, em vez de simplesmente encará-la como uma variável a interferir no processo". 
Adicionalmente, essa proposta está centrada no caráter exploratório, sendo fundamentada no objetivo de desenvolver, esclarecer e modificar conceitos e ideias. Ruiz (1996) assinala que esse tipo de pesquisa caracteriza-se por fornecer critérios sobre a situação-problema e identificar cursos alternativos de ação.

Por sua vez, o método de investigação é o estudo de caso, onde Yin (2003, p. 32) contempla que "um estudo de caso é uma investigação empírica que analisa um fenômeno contemporâneo dentro do seu contexto, especialmente quando os limites entre o fenômeno e o contexto não estão claramente definidos".

O caso a ser estudado envolve uma cooperativa do ramo de serviços localizada na cidade de Santa Maria (RS) e, conforme já mencionado, se denominará Cooperativa Beta. Esta opera com 124 cooperativas de crédito e mais de 1.000 pontos de atendimento em onze Estados brasileiros (Rio Grande do Sul, Santa Catarina, Paraná, Mato Grosso, Mato Grosso do Sul, Tocantins, Pará, Rondônia, Goiás, São Paulo e Bahia). A organização em sistema, com cinco Cooperativas Centrais, Confederação, Banco Cooperativo e empresas controladas. Com origem essencialmente no setor primário, a Cooperativa Beta atua nos centros urbanos, por intermédio das cooperativas de livre admissão e/ou por meio de cooperativas de crédito segmentadas, que são aquelas ligadas a categorias profissionais ou segmentos econômicos específicos.

Esse contexto de estudo de caso se justifica para compreender as dinâmicas do intraempreendedorismo e suas implicações na gestão no panorama das características das organizações cooperativas. Merece atenção, também, o fato de que essa organização é constituída sob a lógica da cooperação e a união de pessoas com objetivos comuns é um dos seus princípios. No entanto, de modo controverso ao que aponta a literatura e do que é verificado, essas organizações ainda carecem de maior aporte para qualificar seus modelos de gestão e no desenvolvimento e fortalecimento de lideranças por meio da ação empreendedora.

Para dar suporte a esse processo, estes relacionamentos foram estudados a partir das dimensões das racionalidades empreendedoras e intraempreendedoras, confrontadas com o modelo de gestão organizacional praticado. Isso se faz necessário, uma vez que por meio dessa comparação, entende-se ser possível identificar e avaliar essas duas dimensões e de que forma elas são aplicadas em termos efetivos. 
Para coleta dos dados, foram adotados os métodos da comunicação, observação e análise documental. Para Minayo (1994) a comunicação é uma forma de questionamento verbal ou escrito dos respondentes para a obtenção do dado desejado, fornecido pelo próprio entrevistado. Em se tratando de entrevistas, estas foram direcionadas ao presidente da cooperativa e mais três pessoas ligadas diretamente a ele para que se pudesse confrontar as respostas de modo geral. Para a seleção dessas pessoas se lançou mão do organograma da Cooperativa, para identificar os cargos próximos ao presidente. A análise documental contou basicamente com análise de estatuto e atas de reuniões realizadas, bem como de outros documentos sobre algumas atividades e processos da cooperativa de modo a entender como se dá a formalização do processo intraempreendedor. A observação direta serviu para analisar as rotinas do trabalho do presidente tanto no que se refere ao seu trabalho individual, de construção de ideias, mas, essencialmente, observar sua relação com as demais pessoas envolvidas em todas as ações da cooperativa. Como aporte dessa análise, buscou-se conhecer os processos e as técnicas utilizadas quanto aos aspectos do fundamento intraempreededor, bem como o tipo e intensidade das ações desenvolvidas a partir da forma organizacional adotada. O modelo teórico já descrito foi necessário para dar o suporte para a realização desses processos na sua plenitude.

Com base nessas técnicas, foi possível promover a análise das informações obtidas. Conforme Lakatos e Marconi (2001), a análise dos resultados tem como objetivo principal permitir ao pesquisador o estabelecimento das conclusões. Sendo assim, durante a realização desse procedimento adotou-se as técnicas de classificação, categorização e, essencialmente, a análise qualitativa de conteúdo. A partir disso, foram realizadas as análises descritivas e o confronto teórico. Para tanto, procedeu-se a análise das informações qualitativas, que foi feita sob a ótica da análise de conteúdo e ao longo do processo de discussão dos resultados, no qual estas informações serviram como elementos de aprofundamento e entendimento. A análise de conteúdo é uma técnica de pesquisa que pode tornar retráteis e válidas as inferências dos dados referentes ao seu contexto (BELL, 2008). Existem várias formas de se analisar o conteúdo, contudo é importante verificar, primeiramente, o que se quer com as questões. Nesse processo o pesquisador procura construir 
um conhecimento analisando o discurso, a disposição e os termos utilizados pelos entrevistados. Como aporte para esse item da pesquisa, utilizou-se também o método dedutivo, com o objetivo de verificar as implicações da racionalidade intraempreendedora nas atividades da Cooperativa.

Dessa forma, espera-se que esses aspectos tenham possibilitado o levantamento de resultados apropriados, de maneira que se possam promover inferências concretas para se avaliar o perfil intraempreendedor aplicado na Cooperativa Beta.

\section{DIAGNÓSTICO INTRAEMPREENDEDOR}

De modo a oferecer orientação específica para esse item do trabalho, serão tomados como elementos de análise prática e confronto teórico as características estudadas ao longo da pesquisa e suas correlações com o modelo proposto para análise, exposto no referencial teórico desse estudo.

Com base no que foi teorizado no referencial, serão analisados nesse capítulo os itens identificados como características intraempreendedoras na ótica de Man e Lau (2000), sendo eles: busca de oportunidades, riscos calculados, comprometimento, informações, metas, planejamento e monitoramento, persuasão e redes de contatos.

Para o presidente da Cooperativa Beta, a busca de oportunidades se torna uma das prerrogativas mais fundamentais da questão intraempreendedora, e o mesmo justifica isso discorrendo que " [...] estar atento a um ambiente extremamente competitivo e ao mesmo tempo desafiador é fundamental para a permanência da cooperativa no mercado". Concordando com isso, os colaboradores entrevistados destacaram que uma das ações que o presidente da cooperativa teve foi de apoiar e participar da consolidação de uma parceria com um banco cooperativo mundial, que sem dúvida foi uma das principais iniciativas adotada na sua gestão. Na opinião dos colaboradores, a participação do presidente foi muito importante para fortalecer essa proposta e fomentar as ações que vinham sendo desenvolvidas.

Conforme um dos entrevistados, "em 2010 a Cooperativa firmou uma parceria com o braço de desenvolvimento do grupo holandês Rabobank, sistema 
de crédito cooperativo holandês presente em 40 países. Mediante participação minoritária, o sistema holandês passa a transferir sua expertise de 160 anos de organização e, ao mesmo tempo, através da Cooperativa Beta, investir nas atividades econômicas do quadro associativo das cooperativas de crédito que o integram". O presidente complementa ainda que "[...] clientes, fornecedores e concorrentes só existem quando pessoas ou empresas procuram produtos ou serviços e outras pessoas ou empresas oferecem esses mesmos produtos ou serviços". A relação entre a oferta e a procura de produtos e serviços é o mercado. Com isso, se faz necessária a organização de um conjunto de ações, como por exemplo: estar atento às oportunidades, conhecer os valores e as necessidades do cliente-alvo e o que leva o mesmo a comprar, identificar o mercado concorrente verificando quais as empresas que estão competindo, bem como avaliar o potencial dos fornecedores de modo a agregar valor ao produto ou serviço oferecido.

Outra questão mencionada refere-se ao perfil de uma organização como a Cooperativa Beta. Conforme um dos colaboradores entrevistados, "uma organziação como a nossa, formada pela associação autônoma de pessoas, unidas voluntariamente, para prestar serviços financeiros a seus associados. E atuar numa cooperativa como a nossa é muito mais do que um trabalho, pois o colaborador sabe que faz parte de um empreendimento com um modelo diferente, moderno e sustentável".

Nesse mesmo item, o presidente da cooperativa menciona que "participamos naturalmente da vida dos associados com um círculo virtuoso. As cooperativas promovem a educação, o empreendedorismo, agregam renda, geram oportunidades de negócio e contribuem para o desenvolvimento da região. E os resultados são reinvestidos na própria região de atuação, fomentando assim novos negócios e novos investimentos".

O segundo critério investigado intentou sobre a questão dos riscos calculados. Ficou evidente que essa questão também demanda cuidados, uma vez que cada ação empreendida necessita de cuidados especiais quanto à análise do grau de risco envolvido. Para o presidente da Cooperativa Beta "é preciso que cada uma das ações a serem definidas sejam analisadas com critério para medir o risco envolvido. Ainda mais sendo uma cooperativa no setor de serviços, onde os 
riscos somente podem ser mensurados pela percepção da satisfação dos clientes associados".

Ainda na opinião do presidente, "empreender é assumir riscos, porém, existem diversas estratégias que podem ser adotadas para controlar determinados riscos. Dessa forma, entendo que a relação empreendedor e riscos envolvidos é muito intensa e fundamentada por uma realidade que mostra que os empreendedores de sucesso têm, entre suas características mais comuns, a capacidade de correr riscos de forma calculada".

Para os colaboradores, um dos controles que a cooperativa adota está na questão da tomada de decisão, onde são sempre definidas em assembleia diante dos cooperados e também onde os riscos de cada decisão precisam ser expostos com clareza. Uma consideração relevante no contexto de análise dos riscos está presente na política de qualidade em serviços adotada.

Seguindo a análise desse item de pesquisa, conforme um dos entrevistados, "uma política de qualidade clara orienta as decisões organizacionais e permite avaliação mais efetiva dos riscos". Na opinião do presidente "a qualidade em serviços é essencial, pois é ela que vai fazer com que tenhamos condições de melhorar aquilo que fazemos, agregando valor ao nosso negócio e fazendo com que o investimento do nosso associado também cresça. É minha função como presidente buscar constantemente a qualidade nos serviços que prestamos, pois assim posso cobrar dos meus colaboradores e, se eu não fizer isso, não tenho como cobrar melhorias".

$\mathrm{Na}$ opinião de um dos entrevistados a importância do controle que a cooperativa faz está evidente na análise dos riscos, pois "quando uma política de qualidade está presente, como no nosso caso, temos condições de avaliar nossas decisões com base no impacto que estas podem trazer para a Cooperativa Beta, seus colaboradores e nossos associados".

Outro entrevistado apontou que "uma das formas de se trabalhar qualidade e eficiência está na gestão e na adoção por completo dos princípios cooperativos". Para o mesmo entrevistado, "a preocupação com o nosso cooperado é constante, pois se eles não estiverem satisfeitos com os serviços e produtos, nós não estamos trabalhando com qualidade e isso precisa ser revisto".

$\mathrm{O}$ terceiro item de análise envolve o comprometimento, no qual o presidente mencionou que "o nosso comprometimento é com os acontecimentos 
globais da Cooperativa, no qual reflete diretamente nos nossos associados. Precisamos reconhecer que mais do que profissionais, representamos pessoas e essas pessoas esperam de nós o máximo de compromisso. Nossos colaboradores precisam dessa imagem, pois eles se espelham naquilo que fazemos".

Para outro entrevistado, "a busca do comprometimento de todos é constante, pois estamos envolvidos no objetivo central de cooperar e fazer prosperar os investimentos dos nossos associados". Dessa forma, foi possível observar que as cooperativas vinculadas à cooperativa desenvolvem mais de 100 ações sociais e procuram cooperar com iniciativas locais, potencializando um ciclo de compromisso entre empresa e comunidade.

Outro entrevistado apontou que "é do nosso cotidiano prezar pelo comprometimento, através de uma relação entre cooperativa, nossos associados e a comunidade. E essa relação é fruto dos atributos da cooperativa, dentre eles a cultura e os valores". O mesmo entrevistado ainda assinalou que "o fato da cooperativa explicitar os objetivos e as regras de conduta é um fator importante para gerar o comprometimento necessário, pois ao mesmo tempo que deixa claro quais são os resultados desejados, demonstra quais são as atitudes necessárias para isso".

$\mathrm{O}$ quarto critério de análise está nas questões que norteiam as informações. Aqui tomou-se como base a segurança da informação interna e foi observado que o presidente da cooperativa tem à sua disposição um sistema de informação formalizado, onde a busca e uso das informações está presente no sistema adotado, com ênfase na política de privacidade. "Essa política enfatiza o compromisso e respeito da cooperativa em relação à segurança e privacidade das informações dos usuários coletados pelo nosso site". O mesmo salienta que "nossa cooperativa emprega as melhores práticas de mercado com o objetivo de assegurar a confidencialidade, disponibilidade e integridade no acesso ao seu site corporativo, bem como nas transações efetuadas pelo sistema. Com base nesta premissa, mantém pessoal capacitado e em constante treinamento, além de possuir processos e tecnologias que visam o bom funcionamento dos sistemas para o atendimento das demandas dos seus associados e dos visitantes do site corporativo".

Para os demais entrevistados essa questão também é essencial, pois "as políticas de privacidade demonstram os valores da instituição e estão em comum 
acordo com o seu negócio, abrangendo os serviços ofertados. É um compromisso baseado nas regras de condutas definidas para garantir, dessa forma, a melhoria contínua dos sistemas de segurança, assim como a eficácia do processamento das informações".

$\mathrm{O}$ quinto e o sexto critérios de análise são as questões que instigam as metas e o planejamento e monitoramento. Quanto às metas, o presidente da cooperativa relata que a mesma possui "um modelo estratégico de plano de metas". Esse modelo visa estabelecer metas técnicas formuladas através de informações e análises de indicadores alinhadas com as ações a serem desenvolvidas pelas Unidades de Negócios da Cooperativa.

O planejamento é considerado um processo de gestão, e não um evento pontual e esporádico. $\mathrm{O}$ processo compromete todos os níveis da organização e tem supremacia sobre todos os planos de trabalho e iniciativas das entidades que compõem o sistema. Todos os meses, relatórios de acompanhamento são gerados e discutidos de forma geral.

O modelo de governança do planejamento estratégico estabelece que cada uma das iniciativas conta com um responsável pelo desenvolvimento do plano, controle de custos e de investimentos, coordenação com as centrais e cooperativas, comunicação e realização de treinamentos necessários para promover uma implementação bem sucedida. Além disso, sempre que um planejamento é proposto, forma-se um grupo técnico que analisa e propõe possíveis ações que aumentem a sinergia entre os planos, e que também coordena a execução das ações e garante a implantação ordenada das iniciativas. O acompanhamento da evolução do planejamento estratégico é realizado através da mensuração dos indicadores estruturados em cinco grandes grupos: crescimento, eficiência, relacionamento, engajamento e estrutura sistêmica.

Para os demais entrevistados, o presidente "gerencia minunciosamente essa ferramenta, que se constitui através de um sistema de processamento de dados", no qual citam IPP (mede a utilização dos produtos e serviços sobre a base de associados existentes), ticket médio (mede o saldo médio utilizado pelo associado), saldo (mede o total da carteira financeira do produto ou serviço oferecido), e quantidade (mede a quantidade de associados para cada serviço ofertado). Com essa ferramenta gerencial, o presidente recebe dos gerentes de cada unidade da 
Cooperativa um parâmetro numérico com datas e informações quantitativas para o estabelecimento do próximo objetivo.

Quanto ao aspecto do planejamento, o presidente relata que "desenvolveuse na cooperativa um estatuto interno que considera adequado para a unidade da Cooperativa, de forma que ficassem evidenciados e documentados os procedimentos e as ações a serem tomadas, de acordo com aquilo que foi planejado, tarefa esta desempenhada pelos gerentes de cada setor de negócio".

Em relação a esse estatuto, somente quem tem acesso a esse documento é o nível estratégico, porém, os colaboradores são informados e orientados quanto às medidas que foram estabelecidas, através de reuniões mensais. Esse documento engloba basicamente fixação de despesas, estimativas de receitas, controle orçamentário, medidas de produção das pessoas, monitoramento de atividades internas, dentre outros.

Em contrapartida, o presidente discorre que o ponto mais limitante da Cooperativa está na questão do monitoramento sistemático. Para ele, "mesmo que adote um sistema de informações gerenciais, ainda carece de um método com maior eficácia para monitorar seus processos". Porém, ele afirma que "temos uma ferramenta que dá o devido suporte para esse monitoramento, pois a cada entrega realizada, é solicitada uma avaliação das centrais e das cooperativas. Trata-se de um passo considerado muito importante para o sucesso do planejamento estratégico. As avaliações são on-line e direcionadas aos envolvidos. O ciclo dura 180 dias e é uma oportunidade dos colaboradores participarem efetivamente, contribuindo para melhorias contínuas nas entregas".

Com base nessas considerações, tem-se a oportunidade de atender a uma demanda desse estudo que remete a oferecer subsídios para melhoria do empreendimento cooperativo, além de proporcionar ampliação das discussões nesse campo da ciência. Nesse sentido, sugere-se à Cooperativa da adoção de um sistema de controle interno que torne possível melhor monitoramento dos processos da organização e de que forma estes poderão afetar positiva ou negativamente seus resultados.

Nesse estudo o modelo teórico que orienta essa proposta fundamenta-se nas considerações de Crepaldi (2007), no qual o autor apresenta um modelo de controle interno que consiste em um conjunto de princípios que são direcionados para monitorar processos. De forma a atender às necessidades da Cooperativa Beta, 
foram selecionados quatro princípios do modelo que foram considerados mais relevantes para a limitação da Cooperativa, sendo eles: princípio da responsabilidade, princípio de rotinas internas de controle, princípio de segregação de funções e, por fim, princípio de auditoria interna. $O$ princípio da responsabilidade indica atribuições para os funcionários, devendo ser claramente definidos e limitados, de preferência por escrito, mediante as normas estabelecidas pela administração da empresa. As razões para se definir essas atribuições são: assegurar que todo o procedimento interno da empresa esteja sendo realizado de forma correta, detectar erros e irregularidades, apurar as responsabilidades por eventuais omissões, erros ou outro tipo de falha. De acordo com o autor, o princípio de rotinas internas de controle indica a utilização de instrumentos de controles internos, ou seja, formulários contínuos com seguência numérica, carimbos com data e assinatura, autorizações por escrito e outros mecanismos que evidenciam e garantem que os procedimentos de controles internos sejam executados conforme as normas legais e normas impostas pela empresa. O princípio de segregação de funções consiste em que uma pessoa não tenha o domínio completo sobre determinada operação. É uma medida preventiva que para qualquer erro intencional ou não seja possível ser detectado de imediato por outra pessoa. Por sua vez, o princípio de auditoria interna pode-se afirmar que é o mais importante, devido ao fato que a falta de observância deste pode consistir no não funcionamento dos demais, de modo que não adianta a empresa implantar um excelente sistema de controle interno sem que alguém verifique periodicamente se os funcionários estão cumprindo o que foi determinado, ou se há necessidade de serem adaptadas novas técnicas adequadas às condições inerentes "as atividades da organização". Assim, os objetivos da auditoria interna são: verificar se as normas internas estão sendo seguidas, avaliar necessidades de novas normas internas ou de notificações das já existentes, analisar se os processos estão de acordo com o que foi determinado pelos dirigentes, identificar irregularidades nos processos realizando orientações, dentre outros (CREPALDI, 2007).

Dando continuidade à análise dos resultados, o último critério das características intraempreendedoras está na questão que tange a persuasão e rede de contatos. Para o presidente da Cooperativa Beta, este quesito é extremamente relevante nas características intraempreendedoras. O mesmo afirma isto "pelo fato 
da comunicação e a informação com os seus associados serem fundamentais para a permanência da Cooperativa no mercado". O presidente justifica discorrendo que “a persuasão e redes de contatos é a base para união do 'espírito cooperativo' da cooperativa sendo a mais moderna ferramenta de gestão e tecnologia", colocando-a em um posicionamento bastante favorável frente ao mercado e seus associados. $\mathrm{Na}$ visão dos demais entrevistados, o presidente encara a persuasão como uma estratégia de convencer, ou seja, sensibilizar o cliente, vender a ideia. Para o presidente, o intraempreendedor é aquela pessoa inserida dentro da organização que se vale de estratégias deliberadas para influenciar ou persuadir outros, que utiliza pessoaschave como agentes para atingir seus próprios objetivos e que age com ousadia para manter relações comerciais.

Quanto aos demais entrevistados, um deles mencionou que "um bom gestor deve ter a habilidade para negociar, tanto com seus superiores como com seus subordinados. A negociação deve ter a capacidade de convencer as pessoas de que sua ideia é viável. E essa é uma característica marcante do nosso presidente". Para outro entrevistado, "através de sua visão e de suas ideias, as pessoas se convencem e se aceitam a liderança do nosso presidente, pois acreditam no trabalho e na dedicação dele".

Em suma, esses resultados deram o suporte necessário para perceber claramente as questões pertinentes à proposta do trabalho e dar condições essenciais para analisar o perfil intraempreededor adotado na Cooperativa Beta.

\section{CONSIDERAÇÕES FINAIS}

Ao retomar algumas considerações observadas ao longo da discussão dos resultados, remete elucidar que na análise do primeiro critério das características intraempreendedoras do presidente da Cooperativa Beta, a busca de oportunidades, há um indicativo no atendimento desse item, tanto pela fala do presidente como também dos demais entrevistados, uma vez que destaca relativa procura de novas oportunidades, estando atento às novas tendências de mercado.

$\mathrm{Na}$ questão dos riscos calculados, ficou explícito que esse critério o presidente demanda extremos cuidados, uma vez que cada ação empreendida 
necessita de cuidados especiais quanto à análise do grau de risco envolvido. Dessa forma, todas as decisões a serem tomadas são discutidas e votadas exaustivamente em assembleia, para que todos os cooperados estejam cientes das definições debatidas.

O próximo critério de análise foi o comprometimento, que ganhou destaque sob a ótica da apresentação da preocupação do presidente com a sustentabilidade da Cooperativa Beta, especialmente na manutenção do negócio e na fidelização dos cooperados, buscando a credibilidade da imagem.

No critério de análise que tange informações, constatou-se que o presidente da Cooperativa Beta adotou um sistema de informação que se apresenta com alto grau de formalização, onde a busca e uso das informações estão presentes no sistema adotado. Através desse sistema, o presidente consegue gerar informações e ao mesmo tempo oferecer segurança e privacidade a cada cooperado.

Em termos de metas, o presidente transpareceu que são transmitidas com clareza e são entendidas e aceitas por todos na Cooperativa, observando que estas são específicas a cada função e estão diretamente associadas ao planejamento estratégico, por meio de indicadores de desempenho.

Em termos de planejamento foi possível perceber que o presidente associa esta prática à busca constante da eficácia das operações de uma forma geral, tanto por meio de ações informais como também através de ações objetivas por meio de instrumentos formalizados no estatuto.

Porém, no critério de análise que tange o monitoramento, foi relatado pelo presidente uma limitação na monitoração sistématica dos processos, no qual a Cooperativa carece de um método com maior eficácia para monitorar seus processos. Com isso, foi possível contribuir propondo um modelo de controle interno adequado a essa necessidade.

O último critério que foi observado trata-se da persuasão e redes de contatos. Essa característica ficou parcialmente evidente no perfil do presidente, pois tem como características a habilidade para negociar, tanto com seus superiores como com seus subordinados e, ainda, através de sua visão e de suas ideias, as pessoas se convencem e aceitam a liderança do nosso presidente, pois acreditam no trabalho e na dedicação dele.

Para concluir, constatou-se que o objetivo traçado no início do trabalho foi alcançado, pois foi possível identificar as ações intraempreendedoras desempenhadas 
pelo presidente da Cooperativa Beta e de que forma elas interferem na gestão, especialmente pelo confronto das respostas dos entrevistados. Assim, a presente pesquisa possibilitou um maior entendimento sobre o intraempreendedorismo e suas implicações na gestão das organizações cooperativas, temática essa importante para ampliação dos conhecimentos nos estudos organizacionais.

\section{REFERÊNCIAS}

ARANHA, M. L. A.; MARTINS, M. H. P. Filosofando: introdução à filosofia. 2. ed. São Paulo: Moderna, 2001.

BARON, R. A.; SHANE, S. A. Empreendedorismo: uma visão do processo. São Paulo: Cengage Learning, 2010.

BELL, J. Projeto de pesquisa. Porto Alegre: Artmed, 2008.

CASSEL, C.; SYMON, G. Qualitative methods in organizational research. London: Sage Publications, 1994.

CLEGG, S. R.; HARDY, C.; NORD, W. R. Handbook de estudos organizacionais. São Paulo: Atlas, 1999.

CLEGG, S. R. Modern organizations: organization studies in the postmodern world. London: Sage Publications, 1990.

COOPER, R.; BURRELL, G. Modernism, postmodernism and organization analysis: an introduction. Organization Studies, v. 9, n. 1, p. 91-112, 1988.

CREPALDI, S. Auditoria contábil teoria e prática. São Paulo: Atlas, 2007.

DELLAGNELO, E. L.; SILVA, C. L. M. Novas formas organizacionais: onde se encontram as evidências empíricas de ruptura com o modelo burocrático de organizações? $\mathbf{O}$ \& S, v. 5, n. 19, p. 19-33, 2000.

DORNELAS, J. Empreendedorismo: transformando ideias em negócios. Rio de Janeiro: Elsevier, 2012.

FLEURY, A.; FLEURY, M. T. L. Estratégias empresariais e formação de 
competências: um quebra-cabeça caleidoscópio da indústria brasileira. São Paulo: Atlas, 2000.

FLICK, U. Introdução à pesquisa qualitativa. Porto Alegre: Artmed, 2009.

GLOBAL ENTREPRENEURSHIP MONITOR. Empreendedorismo no Brasil - 2000: relatório nacional. Curitiba: IBQP, 2001.

HASHIMOTO, M. Organizações intraempreendedoras: construindo a ponte entre clima interno e desempenho superior. Tese (Doutorado em Administração) - Programa de Pós-Graduação em Administração: Fundação Getúlio Vargas, 2009.

LAKATOS, E. M.; MARCONI, M. de A. Metodologia do trabalho científico: procedimentos básicos, pesquisa bibliográfica, projeto e relatório, publicações e trabalhos científicos. São Paulo: Atlas, 2001.

MAN, T. W. Y.; LAU, T. Entrepreneurial competencies of SME owner/manager in the Hong Kong services sector: a qualitative analysis. Journal of Enterprising Culture, v. 8 , n. 3, p. 235-254, 2000.

MAXIMIANO, A. C. Administração para empreendedores: fundamentos da criação e da gestão de novos negócios. São Paulo: Pearson Prentice Hall, 2006.

McCLELLAND, D. A sociedade competitiva: realização e progresso social. Rio de Janeiro: Expressão e cultura, 1972.

MINAYO, M. C. de S. (Org.). Pesquisa social. Rio de Janeiro: Vozes, 1994.

MOUSTAKAS, C. Phenomenological research methods. Thousand Oaks: Sage Publications, 1994.

NASSIF, V. M. J.; GHOBRIL, A. N.; SILVA, N. S. Understanding the entrepreneurial process: a dynamic approach. BAR, v. 7, n. 2, p. 213-226, 2010.

NASSIF, V. M. J.; ANDRESSI, T.; SIMÕES, F. Competências empreendedoras: há diferenças entre empreendedores e intraempreendedores. RAI, São Paulo, v. 8, n. 3, p. 33-54, 2011.

PARKER, M. Post-moderm organizations or postmodern organization theory? Organization Studies, v. 13, n. 1, p. 35-54, 1992. 
PINCHOT, G. Intrapreneuring: por que você não precisa deixar a empresa para tornar-se um empreendedor. São Paulo: Harbra, 1985.

RUIZ, J. A. Metodologia científica. São Paulo: Atlas, 1996.

SCHUMPETER, J. A. Teoria do desenvolvimento econômico: uma investigação sobre lucros, capital, crédito, juro e o ciclo econômico. São Paulo: Nova Cultural, 1985.

THOMPSON, P. Postmodernism: fatal distraction. In: HASSARD, J.; PARKER, M. Postmodernism and organizations. London: Sage Publications, 1993.

TRIVIÑOS, A. N. S. Introdução à pesquisa em ciências sociais. São Paulo: Atlas, 1987.

TSOUKAS, H. Postmodernism, reflexive rationalism and organizational studies. Organization Studies, v. 13, n. 4, p. 643-650, 1992.

YIN, R. K. Estudo de caso: planejamento e métodos. Porto Alegre: Bookman, 2003.

Recebido em: 23 de outubro de 2013 Aceito em: 27 de janeiro de 2016 